\title{
Blood and vein-wall fibrinolytic activity in health and vascular disease
}

\author{
N L BROWSE, L GRAY, P E M JARRETT, M MORLAND
}

British Medical fournal, 1977, 1, 478-481

\begin{abstract}
Summary
The resting blood fibrinolytic activity of 120 normal subjects and 294 patients with various forms of vascular disease was assessed by measuring the dilute blood clot lysis time and fibrin plate lysis area before and after 10 minutes of venous congestion. The tissue fibrinolytic activity of several of these subjects was assessed in vein biopsy specimens. The results suggested that there was a correlation between blood and tissue fibrinolytic activity and that certain venous diseases, particularly recurrent superficial thrombophlebitis and venous liposclerosis, were associated with a deficiency of blood and tissue fibrinolytic activity.
\end{abstract}

\section{Introduction}

The presence of a substance in the wall of the peripheral veins that activates fibrinolysis was shown by Todd in 1959. ${ }^{1}$ Two years later Clarke et al ${ }^{2}$ showed that venous congestion increased the fibrinolytic activity of venous blood. These and subsequent similar observations have led to the concept that the intrinsic fibrinolytic activity of the blood results from the release of activator from stores in the peripheral veins. It is therefore reasonable to postulate that these stores may be abnormal in people with thrombotic disease-a hypothesis strongly supported by the work of Nilsson et al. ${ }^{3}$

We present here an assessment of the level of fibrinolytic activity in the peripheral venous blood and of activator activity in the vein wall of healthy patients and volunteers and compare them with activity in patients with various vascular diseases. We wanted to determine "normal" values, to see whether there was a correlation between blood and tissue fibrinolytic activity, and to find out whether there was any abnormality of fibrinolysis in patients with vascular disease.

\section{Patients and methods}

Blood was taken from 414 healthy volunteers and patients to estimate indices of fibrinolytic activity-dilute blood clot lysis time (DBCLT) and fibrin plate lysis area (FPLA). Vein biopsy specimens were also taken from some patients.

\section{NORMAL SUBJECTS}

Normal healthy ambulant subjects-These were 32 colleagues who volunteered to give blood samples. Vein biopsies were not performed.

Department of Surgery, St Thomas's Hospital, London SE1 7EH N L BROWSE, MD, FRCS, professor of vascular surgery L GRAY, MB, BS, honorary senior registrar

P E M JARRETT, FRCS, DOBSTRCOG, senior surgical registrar M MORLAND, BSC, technician
"Healthy" inpatients-Eighty-eight patients were admitted for surgery for local disease. These conditions-for example, hernia, gall stones, peptic ulcers-are not, to the best of our knowledge, associated with a generalised abnormality. We took blood samples from these patients after they had been in hospital one or two days. Segments of vein from the hand, groin, and foot were removed under general anaesthesia from some of these patients who were undergoing routine operations such as herniorrhaphy.

\section{PATIENTS WITH ARTERIAL DISEASE}

Patients with atherosclerosis-Forty-two patients had symptoms and arteriographic evidence of atherosclerotic peripheral arterial disease. All were leading a normal life and attending the outpatient clinic. Hand vein biopsies were performed in 10 of these patients when they underwent minor surgery. Biopsy specimens were not taken after long arterial operations because the patients had been given heparin and sometimes blood.

Patients with Buerger's disease-Nine young male outpatients were also studied. All smoked, had experienced episodes of superficial thrombophlebitis, and had symptoms and arteriographic evidence of arterial ischaemia due to small vessel occlusions.

Patients with idiopathic Raynaud's disease-Blood was obtained from 14 patients (four men and 10 women) with longstanding (6-15 years) severe Raynaud's syndrome but with no evidence of systemic disease such as scleroderma. We considered it unethical to perform hand-vein biopsies in these patients with ischaemic hands.

Patients with Raynaud's syndrome secondary to scleroderma-Blood samples were obtained from two men and 19 women with ischaemia of their finger tips and Raynaud's syndrome secondary to proved scleroderma (skin biopsies, barium swallow, etc). We did not perform hand vein biopsies.

\section{PATIENTS WITH VENOUS DISEASE}

Patients with recurrent idiopathic superficial thrombophlebitisTwenty-one patients had had reucrrent episodes of superficial thrombophlebitis for at least two years. Some had had symptoms for 10-20 years. None had any evidence of occult malignant disease or any arterial disease. We believe these patients had true idiopathic primary superficial thrombophlebitis. We performed hand biopsies in 13 patients.

Patients with previous deep vein thrombosis-Samples of blood were obtained from 83 patients who had had a definite episode of deep vein thrombosis in the past, proved then or later by phlebography. All had recovered from the acute episode. The shortest interval between taking blood and the thrombosis was six months. Only six were still on anticoagulants.

Patients with uncomplicated varicose veins-Eighteen patients with uncomplicated varicose veins were studied. They had not suffered from superficial or deep vein thrombosis and had no changes in the skin of the lower limbs such as eczema, pigmentation, or ulceration.

Patients with varicose veins and liposclerosis-Some patients with severe varicose veins develop thickening, pigmentation, induration, and ultimely eczema and ulcers in the skin of the lower medial third of the leg, apparently due to minor recurrent superficial thrombophlebitis and extravasation of plasma proteins into the tissues. We call this condition liposclerosis. This group included 39 patients. Seven underwent hand vein biopsy.

PATIENTS WITH NEOPLASTIC DISEASE

The fibrinolytic activity of 47 patients with neoplastic disease was measured because these patients are more susceptible to superficial 
and deep vein thrombosis. All were in hospital suffering from histologically proved adenocarcinoma, principally of the breast, stomach, colon, and prostate.

\section{COLLECTION OF BLOOD}

A 1-ml sample of blood was removed from an arm vein without congesting the veins: $0.1 \mathrm{ml}$ was used for estimating DBCLT and $0.9 \mathrm{ml}$ for measuring FPLA. The samples were taken between 0930 and 1030 . Both the patients and the healthy volunteers fasted until after venepuncture. After the first sample of blood was processed (see below) a pneumatic cuff $(10-\mathrm{cm}$ wide) was placed around the upper arm and inflated to a pressure of $80 \mathrm{~mm} \mathrm{Hg}$ to produce venous congestion. After 10 minutes another sample of blood was taken and the cuff deflated. Ten minutes of congestion was chosen because longer periods cause considerable discomfort. The time required to produce maximum release from the stores has not been determined but it is certainly more than 20 minutes.

\section{ESTIMATION OF BLOOD AND TISSUE FIBRINOLYTIC ACTIVITY}

DBCLT was measured using the technique of Fearnley et al. ${ }^{4}$ FPLA was measured using the technique of Astrup and Mullertz. ${ }^{5}$ Plasma fibrinogen was measured using the technique of Ingram."

Vein wall fibrinolytic activity was measured using a modification of the methods described by Todd ${ }^{1}$ and Pandolfi et al. ${ }^{7}$ Segments of vein $1-\mathrm{cm}$ long were removed from the back of the hand using local anaesthetic ( $1^{\circ}$, plain lignocaine). The segments of vein removed during general anaesthesia from patients undergoing operations were always taken at the end of the operation. The vein was dissected with great care and the minimum of trauma.

The specimen was placed in a polyethylene packet and rapidly frozen by being dropped into a beaker of precooled hexane $\left(-20^{\circ} \mathrm{C}\right)$, standing in a dish containing solid carbon dioxide. It was then stored in a deep-freeze in a vacuum flask containing solid carbon dioxide until required. The maximum storage time was three weeks. Pre-

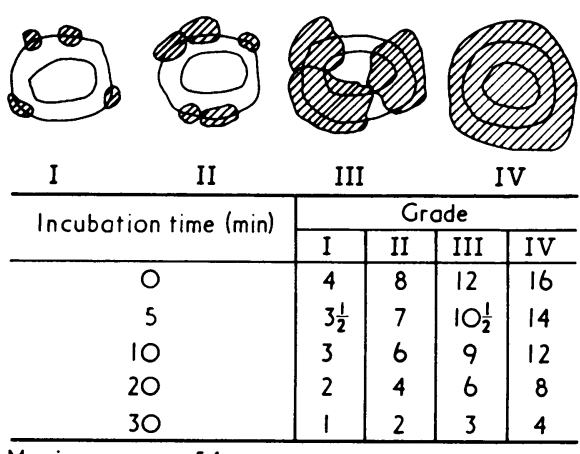

Maximum score $=54$

FIG 1-Definition of four grades of fibrinolysis seen around vein biopsy specimens and method of scoring (see text) liminary studies showed no loss of activity in specimens stored for up to one month.

Slices $7-\mu m$ thick were cut with a cryostat. Fifty slices were placed on five precleaned microscope slides (10 per slide) and each slide was covered with $0.07 \mathrm{ml}$ of mixture of human plasminogen and human fibrinogen ( $150 \mathrm{mg}$ fibrinogen in $10 \mathrm{ml}$ plus 15 casein units of plasminogen in $2.1 \mathrm{ml}$ ). The mixture on each slide was then clotted by adding $0.01 \mathrm{ml}$ of human thrombin $(20 \mathrm{NIH}$ units $/ \mathrm{ml})$. The thickness of the resulting fibrin layer was fairly constant $(60-80: \mathrm{m})$ because the quantity dropped on to the slide was constant and spread over a constant area $\left(10 \mathrm{~cm}^{2}\right)$. All five slides were incubated at room temperature $(20 \mathrm{C})$ in a humidified chamber for 30 minutes to allow the fibrin film to set and then four slides were put in an incubator at $37^{\circ} \mathrm{C}$ for $5,10,20$, and 30 minutes. At the end of its period of incubation each slide was fixed with $10^{\circ}{ }^{\circ}$ buffered formalin ( $\mathrm{pH} 7$ ) and stained with Harris's haematoxylin and Geimsa stain. This produced five slides, each with 10 sections of vein, that had all been incubated at $20 \mathrm{C}$ for 30 minutes and then for $0,5,10,20$, and 30 minutes at $37^{\circ} \mathrm{C}$, respectively.

The degree of fibrinlysis was quantified as follows (fig 1): grade I = small discrete areas; grade $\mathrm{II}=$ larger areas, some just beginning to touch adjacent areas; grade III = confluent areas but not covering the whole specimen; grade IV = one large area of lysis with the section at its centre. The 10 sections on each slide were examined and a grade given for the whole slide. The grades were then scored, as shown in fig 1 , to give weight to both the area of lysis and the time taken for it to appear. The maximum score possible (grade IV on all five slides) was 54.

The nature and purpose of the experiments were explained to the patients and their written consent to venepuncture and vein biopsy obtained.

\section{Results}

The results of the measurements of blood and tissue fibrinolytic activity in each group of subjects are shown in tables I and II.

TABLE II-Vein-wall fibrinolytic activity in normal subjects and patients with various vascular diseases

\begin{tabular}{|c|c|c|c|c|c|c|}
\hline \multicolumn{3}{|c|}{ Subjects } & $\begin{array}{c}\text { No of } \\
\text { patients }\end{array}$ & $\begin{array}{c}\text { Ambulant } \\
\text { or } \\
\text { inpatient }\end{array}$ & Anaesthetic & $\begin{array}{c}\text { Mean } \\
\text { (and SE) } \\
\text { vein wall } \\
\text { activity } \\
\text { (units) }\end{array}$ \\
\hline \multicolumn{3}{|l|}{ Healthy patients: } & & \multirow{4}{*}{ Inpatient } & \multirow{4}{*}{ General } & \\
\hline Hand veins . & .. & . & 17 & & & $24 \quad(2 \cdot 2)$ \\
\hline Groin veins . & & . & & & & 15 \\
\hline $\begin{array}{l}\text { Foot veins } \\
\text { Atherosclerosis: }\end{array}$ & & .. & 12 & & & $18(3 \cdot 0)$ \\
\hline $\begin{array}{l}\text { Atherosclerosis: } \\
\text { Hand veins }\end{array}$ & . & & 10 & Inpatient & General & $16 \cdot 5(4 \cdot 0)$ \\
\hline Buerger's disease: & & & 9 & Ambulant & Local & $20 \cdot 7(2 \cdot 9)$ \\
\hline \multicolumn{2}{|c|}{ Hand veins } & & 13 & Ambulant & Local & $12(1.9)^{*}$ \\
\hline \multicolumn{3}{|c|}{$\begin{array}{l}\text { Previous deep vein thrombosis: } \\
\text { Hand veins }\end{array}$} & 5 & Ambulant & Local & $17 \cdot 5(2 \cdot 2)$ \\
\hline \multicolumn{3}{|c|}{ Varicose veins and liposclerosis: } & & & Local & $12.5(2.0)^{*}$ \\
\hline \multicolumn{3}{|l|}{ Adenocarcinoma: } & 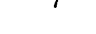 & Amourant & & \\
\hline Hand veins & .. & . & 10 & Inpatient & General & $20 \cdot 4(4 \cdot 0)$ \\
\hline
\end{tabular}

*Significantly different from hand veins of normal subjects.

TABLE I-Blood fibrinolyitc activity in normal subjects and patients with various vascular diseases. Values are means (and SE)

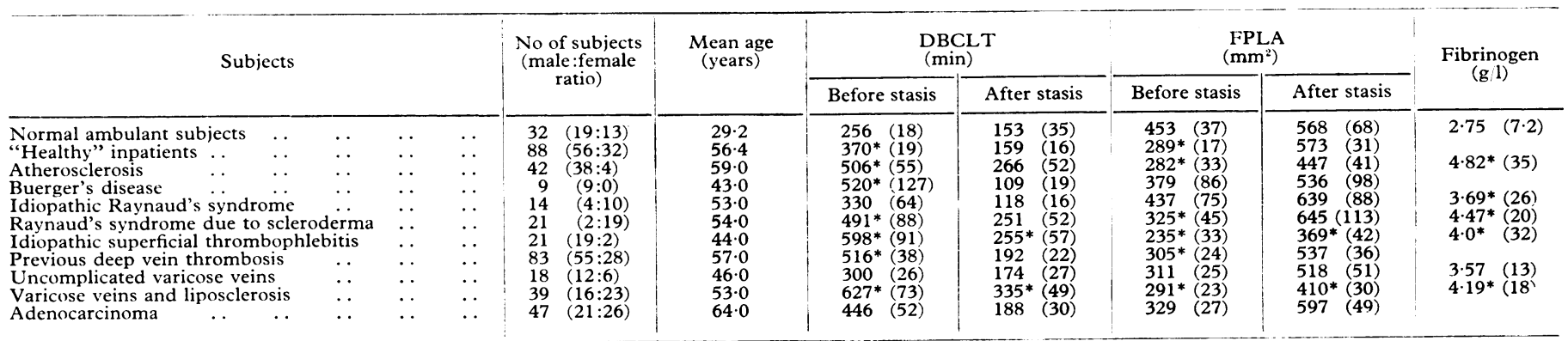

*Significantly different from value of normal ambulant subjects. 
Healthy inpatients-The resting blood fibrinolytic activity was significantly lower than that of the ambulant volunteers $(P=0.001)$. This was probably owing to the patients' inactivity, not the age difference, because a regression analysis within this group failed to show a significant correlation between blood fibrinolytic activity and age. The level of fibrinolytic activity after stasis was not significantly different from that of the ambulant group. Although there was a considerable range of values within this group we thought that they were "normal" and therefore considered the normal range of activity for a hand vein biopsy specimen to lie between 15 and 25 (table II). A score of 12-15 was probably abnormal and a score below 12 definitely abnormal.

Patients with atherosclerosis-The standard errors of the means of these patients' results (table I) show that there was a wide range of blood fibrinolytic activity, but when compared with the values for normal ambulant subjects their resting DBCLT and FPLA and the plasma fibrinogen values were significantly different $(\mathbf{P}=0.001$ in each case). The mean activity of the hand veins was 16.5 units. This was almost significantly different $(P=0.08)$ from the activity in hand veins of normal patients and was at the bottom of the normal range.

Patients with Buerger's disease-The only measurement significantly different from that of normal ambulant subjects was the DBCLT at rest, but this was a small group with widely varying values of fibrinolysis activity. The activity of the hand veins of these patients was normal (20.7 units).

Patients with idiopathic Raynaud's syndrome-The blood fibrinolytic activity of these patients was normal but their plasma fibrinogen value was significantly higher than that of the normal subjects $(P=0.001)$.

Patients with scleroderma-The resting values of DBCLT, FPLA, were significantly lower than those of the normal ambulant subjects $(\mathbf{P}=0.001,0.04$, respectively). The values after stasis were not significantly different. Fibrinogen levels were much higher than normal $(\mathrm{P}=0.0001)$.

Patients with thrombophlebitis-The DBCLT at rest and after stasis and FPLA at rest and after stasis and the plasma fibrinogen level were all significantly different from those of the normal ambulant subjects $(P=0.003,0.03,0.002,0.003$, and 0.0001 respectively) and from the values of the healthy inpatients. The hand-vein biopsy specimens from 13 patients had a mean score of 12.0 , which was significantly lower than that of the ambulant normal subjects $(\mathbf{P}=0.001)$. Some of these patients had very low scores, such as 1,5 , and 6 . One had a score of 26 , which was normal. The scores of the remainder were below 17 , with a mean of 10.4 - far below the normal range.

Patients with previous deep vein thrombosis-The DBCLT and FPLA at rest were significantly lower than those of the ambulant normal people $(P=0.001)$. The hand vein specimens obtained from five of these patients had a mean activity of 17.5 units. This was at the lower end of the normal range, but not quite significantly different from that of the normal ambulant subjects $(P=0.07)$.

Patients with varicose veins had normal blood and tissue fibrinolytic activity.

Patients with varicose veins and liposclerosis-The resting and postcongestion DBCLT, FPLA, and plasma fibrinogen levels of 39 of these patients were significantly abnormal $(P=0.001,0.04,0.01,0.05$, and 0.0001 , respectively). Samples of hand veins from seven patients had a mean activity of 12.5 units-well below normal $(P=0.005)$.

Patients with neoplastic disease had blood and tissue fibrinolytic activity similar to that of the healthy non-ambulant patients.

\section{RELATION BETWEEN TESTS OF FIBRINOLYTIC ACTIVITY}

The results from these 414 patients were analysed to see whether there was any relation between the results of the various tests. Linear regression analyses showed the following relation:

(a) a highly significant relation between FPLA and DBCLT before stasis in individual groups and all patients combined $(0.01<\mathrm{P}>0.001)$;

(b) a highly significant relation between FPLA and DBCLT after stasis in individual groups and all patients combined $(P=0.001)$;

(c) an almost significant relation between tissue activity and DBCLT before stasis when all patients were analysed together $(0.05<\mathrm{P}>0.1)$, but no correlation in individual groups;

(d) no correlation between tissue activity and DBCLT after stasis in individual groups;

(e) no correlation between tissue activity and the decrease of DBCLT caused by stasis in normal subjects;

$(f)$ no correlation between tissue activity and percentage change of DBCLT caused by stasis in normal subjects; (g) no correlation between tissue activity and FPLA as in $c, d, e$, and $f$;

(h) a significant correlation before $(\mathrm{P}<0.0001)$ and after stasis $(P<0.001)$ between plasma fibrinogen and DBCLT in all patients combined. The existence of a relation between these two measurements was shown only when we analysed all patients. Within each subgroup of table I no relation could be shown.

The figures for tissue activity and DBCLT at rest were also examined to detect quadratic or exponential relation, but none were found. Figs 2 and 3 show the mean values of DBCLT and FPLA for each subgroup plotted against their mean tissue activity. There seemed to be a relation between the blood and tissue measurements.

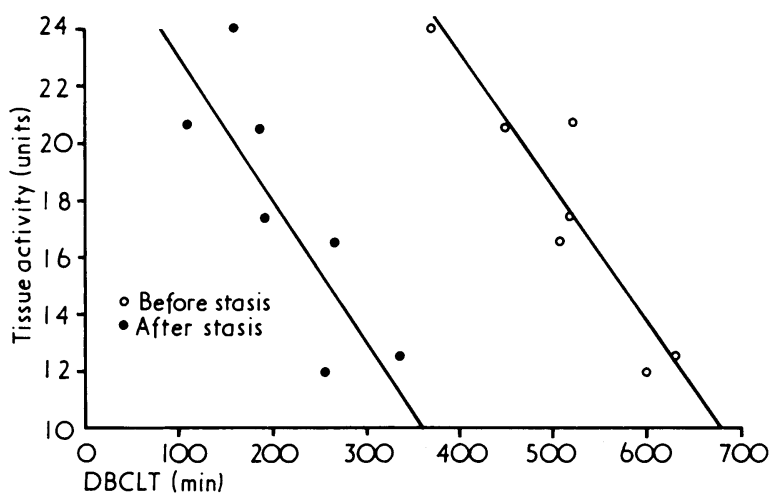

FIG 2-Values of mean tissue activity in seven groups shown in table II plotted against their mean DBCLTs, before and after stasis. Linear regression was calculated using mean values.

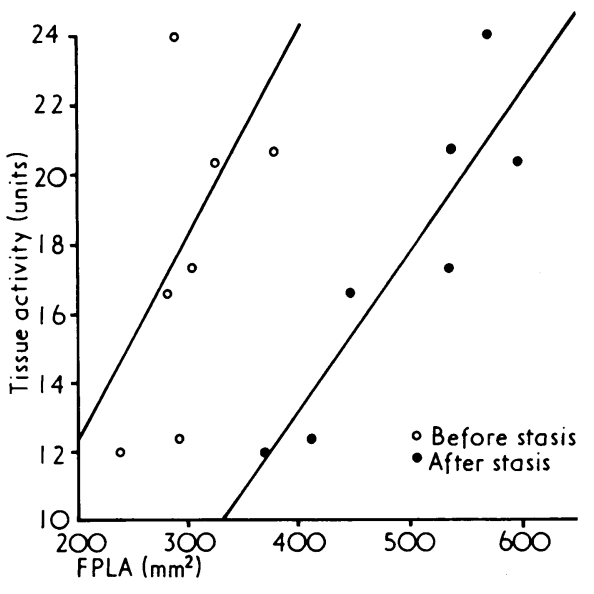

FIG 3-Values of mean tissue activity in seven groups shown in table II plotted against their mean FPLAs, before and after stasis. Linear regression was calculated using the mean values.

This was also suggested by analysis $c$, which would probably have been significant had there been more results in the low tissue activity range. Figs 2 and 3 also show that the mean values of blood fibrinolytic activity before and after stasis ran parallel to each other, which suggested that the response to 10 minutes' stasis was reasonably constant and that both values were related to the size of the tissue stores as measured by the tissue incubation method.

\section{Discussion}

In spite of the problems surrounding the measurement of fibrinolytic activity it is generally accepted that the three indices we have used-the DBCLT, FPLA, and tissue activator activity-do give some indication of fibrinolytic activity.

It has been claimed ${ }^{8}$ that the DBCLT depends on the level 
of plasma fibrinogen. At first sight our results seem to support this view, but we also found a close relation between DBCLT and FPLA. As the FPLA test is independent of plasma fibrinogen levels (the $0.03 \mathrm{ml}$ of the euglobulin fraction put on the fibrin plate can contain, at the most, only $0.09 \mathrm{mg}$ of the patient's own fibrinogen), we conclude that the relation between the plasma fibrinogen and the DBCLT is not that of cause and effect but that they are both similar effects of the changes in fibrinolysis.

It has also been suggested that the response to stasis indicates the ability of the vascular endothelium to release activator, and so, it is argued, the level of activity after stasis is an indication of the size of the peripheral stores. Unfortunately, studies of the effect of prolonged venous congestion show that activity is still increasing after 20 minutes' occlusion. ${ }^{9}$ This period is too long and too uncomfortable for most patients and we have had to accept a 10-minute period of congestion, realising that this may reveal only gross deficiencies in the peripheral stores.

Interpreting the measurement of tissue activity is more difficult. One piece of vein cannot be representative of the whole venous system but it is obviously unjustifiable and impracticable to take multiple vein biopsy specimens. The lack of good statistical correlation between the individual measurements of tissue and blood activity and between tissue activity and the changes in the blood induced by stasis do not exclude the possibility of a relationship. The number of biopsy specimens was small compared with the number of blood tests performed, and the changes observed in an individual will depend on many factors, such as the size of tissue store, the rate of release from the store, the rate of activator destruction or inhibition, and local changes in blood flow. If the tissue stores are large in proportion to the blood levels then small changes in the rate of release from the stores may produce large changes in the blood, without detectable changes in the tissues.

The apparent relation between the mean levels of blood and tissue activity for each group suggest that there is a connection between the blood and tissue activity but it will need many more measurements to prove the point to the statisticians' satisfaction. The linear regression in figs 2 and 3 using the mean values are not valid mathematical analyses, but they do seem to support this thesis. We have not yet found a patient with very low tissue activity and normal blood activity.

Tables I and II show that certain groups of patients have a depressed blood and fibrinolytic activity. Simply restricting normal people to hospital causes a significant depression of activity. This is in accord with the known stimulating effect of exercise on fibrinolytic activity. ${ }^{10}$

Patients with generalised atherosclerosis are known to have a depressed blood fibrinolytic activity at rest. ${ }^{11}$ Our studies agree with this previous work and also suggest that there may be a slight reduction of the stores of tissue activator.

Patients with Buerger's disease and idiopathic Raynaud's syndrome had normal blood and tissue fibrinolytic activity, but those with vascular disease secondary to scleroderma had a definite depression of blood activity at rest.

All the patients with venous thrombotic disease were abnormal. The greatest abnormality was in those with varicose veins and liposclerosis. Not only was their resting level depressed but their level after stasis was also significantly reduced. This finding coupled with a low level of activity in their vein wall suggests that their peripheral stores may be seriously deficient. This may be the underlying abnormality that leads to the liposclerosis and venous ulceration, because patients with uncomplicated varicose veins had normal blood activity.

Patients with adenocarcinoma had normal levels of blood fibrinolytic activity before and after stasis and normal tissue activity, which suggests that their tendency to thrombosis is not caused by a fibrinolytic defect.

This study has taken place over several years and the results were not analysed until recently. The technician who performed the tests had no knowledge of the patients' diseases. The differences between the groups were statistically significant only because we studied large numbers. Because of the wide variations, individual measurements should be interpreted with caution, and any group of patients studied should always be compared with a series of matched controls. Nevertheless, some diseases do seem to be associated with a deficient fibrinolytic system. This deficiency can be graded into two categories.

Grade I-Patients have a reduced resting blood activity with a normal response to stasis (to levels near to normal) and a normal tissue activity. All "healthy" people in hospital and those with atherosclerosis, scleroderma, or deep vein thrombosis are typical examples of patients with this mild deficiency.

Grade II-A reduced resting blood activity, a reduced blood activity after stasis, and a low tissue activity are characteristic of this severe deficiency. Patients with grade II fibrinolytic deficiency include those with venous liposclerosis and recurrent superficial thrombophlebitis.

On the basis of these results we conducted three clinical trials -in patients with scleroderma, thrombophlebitis, and venous liposclerosis-to see whether restoring blood fibrinolytic activity to normal changes the clinical picture. The preliminary results will shortly be published, but we have been encouraged by the fact that the two groups of patients with a grade II fibrinolytic deficiency (those with thrombophlebitis or venous liposclerosis) have had considerable, and sometimes dramatic, relief of their symptoms. The patients with scleroderma (grade I deficiency) have had a smaller, but clinically worthwhile, improvement. These trials therefore support the hypothesis that there are diseases secondary to a fibrinolytic defect and that the correction of this defect might be a worthwhile form of treatment.

We are grateful for the generous support of the British Heart Foundation, the Endowment Fund of St Thomas's Hospital, and Sterling-Winthrop Ltd.

\section{References}

1 Todd, A S, Fournal of Pathology and Bacteriology, 1959, 78, 281.

2 Clarke, R L, Orandi, A, and Cliffton, E F, Angiology, 1960, 11, 367

3 Nilsson, I M, and Isacson, S, Progress in Surgery, 1973, 11, 46.

${ }^{4}$ Fearnley, G R, Balmforth, G V, and Fearnley, E, Clinical Science, 1957, 16,645 .

${ }^{5}$ Astrup, T, and Mullertz, S, Archives of Biochemistry, 1952, 40, 346.

${ }^{6}$ Ingram, G I C, Fournal of Biochemistry, 1952, 51, 583.

7 Pandolfi, M, et al, Lancet, 1967, 2, 127.

8 Hickman, J A, et al, Fournal of Clinical Pathology, 1973, 26, 189.

9 Aberg, M, and Nilsson, I M, Progress in Chemical Fibrinolysis and Thrombolysis. New York, Raven Press, 1975.

1" Ogston, D, and Fullerton, H W, Lancet, 1961, 2, 730.

11 Naimi, S, Goldstein, R, and Proger, S, Circulation, 1963, 27, 904.

(Accepted 22 December 1976) 